\title{
A stochastic rainfall generator model for simulation of daily rainfall events in Kurau catchment: model testing
}

\begin{abstract}
Reservoirs play a substantial role in meeting water demands in arid and semi-arid regions especially with increasing changes in global rainfall patterns. Kurau catchment located at Northwest Perak, Malaysia, is the largest source of water to Bukit Merah Reservoir. Based on climate change effects on rainfall pattern, it is important to develop a model to simulate rainfall occurrence and amount that flow into the reservoir. To address this problem, a stochastic rainfall generator model based on first-order two-state Markov chain approach was developed to simulate long-term daily rainfall series. Rainfall time series for a 30-year period (1976-2006) was assessed. The observed time series data were used as input to the stochastic model to generate a new set of daily time series data. The statistical properties of the new set of data including monthly mean, standard deviation, dry and wet spell lengths were compared with the observed data to gauge the model accuracy. The results obtained were satisfactory, giving motivation in applying the model for generating future rainfall series under different climate change scenarios.
\end{abstract}

Keyword: Stochastic rainfall generator; Climate change; Markov chain; Rainfall; Reservoir; Dry and wet spell lengths 